\title{
Protection, systemic IFN $\gamma$, and antibody responses induced by an ISCOM-based vaccine against a recent equine influenza virus in its natural host
}

\author{
Romain PAILlot ${ }^{1 *}$, Humphrey GRIMMETT ${ }^{2}$, Debra Elton $^{1}$, \\ Janet M. DALY ${ }^{1,3}$

\footnotetext{
${ }^{1}$ Animal Health Trust, Centre for Preventive Medicine, Lanwades Park, Newmarket, Suffolk, CB8 7UU, UK

${ }^{2}$ Schering Plough, Animal Health, Breakspear Rd, South Harefield, Uxbridge, Middlesex, UB9 6LS, UK
} \\ ${ }^{3}$ Present address: Viral Brain Infections Group, University of Liverpool, Daulby Street, Liverpool L69 3GA, UK
}

(Received 31 August 2007; accepted 9 November 2007)

\begin{abstract}
In the horse, conventional inactivated or subunit vaccines against equine influenza virus (EIV) induce a short-lived antibody-based immunity to infection. Alternative strategies of vaccination have been subsequently developed to mimic the long-term protection induced by natural infection with the virus. One of these approaches is the use of immune-stimulating complex (ISCOM)-based vaccines. ISCOM vaccines induce a strong antibody response and protection against influenza in horses, humans, and a mouse model. Cell-mediated immunity (CMI) has been demonstrated in humans and mice after ISCOM vaccination, but rarely investigated in the horse. The aim of this study was to evaluate EIV-specific immune responses after intra-muscular vaccination with an ISCOM-EIV vaccine (EQUIP F) containing both equine influenza H7N7 (A/eq/Newmarket/77) and H3N8 (A/eq/Borlänge/91 and A/eq/Kentucky/98) strains. The antibody response was measured by single radial haemolysis (SRH) assay using different H3N8 EIV strains. Stimulation of type-1 immunity was evaluated with a recently developed method that measures EIV-specific IFN $\gamma$ synthesis by peripheral blood lymphocytes (PBL). The protective efficacy of this ISCOM-based vaccine against challenge infection with a recent equine influenza (H3N8; A/eq/South Africa/4/03) strain was also evaluated. Vaccinated ponies developed elevated levels of EIV-specific SRH antibody and increased percentage of EIV-specific IFN $\gamma^{+}$PBL, whereas these responses were only detected after challenge infection in unvaccinated control ponies. Vaccinates showed minimal signs of disease and did not shed virus when challenged shortly after the second immunisation. In conclusion, evidence of type- 1 immunity induced by an ISCOM-based vaccine is described for the first time in horses.
\end{abstract}

equine influenza virus / vaccine / ISCOM / equine IFN gamma / immunity

\section{INTRODUCTION}

Influenza is a respiratory disease in the horse induced by equine influenza virus (EIV) of the H7N7 and H3N8 subtypes. While the presence of H7N7 EIV has not been detected since 1991 [12], H3N8 EIV is still circulating and the cause of influenza outbreaks in horses ${ }^{1}$

* Corresponding author: romain.paillot@aht.org.uk ${ }^{1}$ Newton R., Elton D., Bryant N., Rash A., Hammond T.A., Equine influenza in England, Letter, Vet. Rec. (2007) 160:851 (letter).
[17], despite widespread vaccination in certain populations. Conventional vaccines against EIV, containing whole inactivated virus or sub-unit antigens, stimulate an antibody-based immune response leading to an efficient, but short-lived and highly specific, immunity to infection. Strategies of vaccination developed in the last decades (reviewed in $[6,18]$ ) aim to mimic the long-term protection induced by natural infection. One of these approaches is the use of immune stimulating complex 
(ISCOM)-based vaccines, which have been used for several years in horses.

ISCOM particles are spontaneously formed, negatively charged, and stable cagelike structures resulting from the combination of antigens with cholesterol, phospholipids, and Quillaja saponins (Quil-A) [30]. ISCOM particles play the role of adjuvant, improving presentation, distribution, and release of the antigen when compared with the soluble protein alone. ISCOMs associate with intracellular lipid membranes and have been localised within the cytoplasm and vesicular compartment in antigen-presenting cells (APC) $[2,37]$. Antigens are therefore processed by both endogenous and exogenous pathways and presented via major histocompatibility complex (MHC) class I and II molecules, respectively [13]. ISCOM adjuvant also induces the synthesis of proinflammatory, Th1 and Th2 cytokines (e.g. TNF $\alpha$, IL-6, IFN $\gamma$ and IL-4), which modulate $\mathrm{T}$ cell immune responses [29, 30]. Upregulation of MHC class II and co-stimulatory molecules in APC has also been demonstrated in mice $[13,26]$.

ISCOM vaccines have been used to induce both humoral and cellular immune responses to numerous antigens in several species [28]. ISCOMs induce a strong and long lasting antibody response against influenza haemagglutinin (HA) and neuraminidase (NA) glycoproteins when compared with conventional adjuvants (e.g. Freund's complete adjuvant or aluminium hydroxide) [31]. In mice, ISCOMinfluenza vaccines protect against experimental challenge infection with homologous or heterologous strains of influenza virus [27, 32]. In humans, administration of ISCOMinfluenza $(\mathrm{H} 1 \mathrm{~N} 1$ or $\mathrm{H} 3 \mathrm{~N} 2)$ vaccine has been shown to accelerate the antibody response and to stimulate $\mathrm{T}$ lymphocyte proliferation and cytotoxic T lymphocyte (CTL) activity [23]. In the horse, ISCOM-vaccines containing EIV antigens have been studied for two decades. These vaccines were shown to induce a high and long-lasting antibody response, when compared with conventional killed whole influenza virus vaccine, and protection against experimental infection with homologous EIV strains ${ }^{2}$ [4, 5, 15, 16, 33]. Stimulation of Th1 T lymphocytes and cellular immune response (type- 1 immunity) after vaccination with ISCOM-based vaccines has been largely described in humans [23] and several animal models [3] but this has not been investigated in vaccinated horses due to a lack of specific methods available for this species. The measurement of virus-specific IFN $\gamma$ synthesis has been recently developed to evaluate stimulation of type-1 immunity after experimental infection with equine respiratory viruses such as equine herpesvirus-1 (EHV-1) [19, 21] or EIV [20], or vaccination with vector-based vaccines specially designed to stimulate an antigen-specific CMI [22].

The aims of this study were to determine whether the current formulation of a commercialised EIV-ISCOM vaccine, containing equine influenza H7N7 strain A/eq/ Newmarket/77 and H3N8 strains A/eq/ Borlänge/91 and A/eq/Kentucky/98, would stimulate both humoral and type-1 immune responses, and protect against challenge infection with a recently circulating equine influenza strain, A/eq/South Africa/4/03 (H3N8), which is the subject of a vaccine strain update recommendation ${ }^{3}$.

\section{MATERIALS AND METHODS}

\subsection{Viruses}

Different strains of EIV were used in this study (Tab. I). EIV strain A/eq/Sussex/89 was used for culture amplification of peripheral blood mononuclear cells (PBMC) and in vitro stimulation. EIV

\footnotetext{
${ }^{2}$ Hannant D., Jessett D.M., O’Neill T., Sundquist B., Mumford J.A., Nasopharyngeal, tracheobronchial, and sytemic immune responses to vaccination and aerosol infection with equine-2 influenza A virus (H3N8), in: Equine Infectious Diseases V: Proceedings of the Fifth International Conference, Powell D.G. (Ed.), University Press of Kentucky: Lexington, KY, USA, 1987, pp. 66-73.

${ }^{3}$ OIE, Conclusion and recommendations from the Expert Surveillance Panel on Equine Influenza Vaccines, 2006, pp. 35-36: http://www.oie.int/ eng/publicat/BULLETIN\%20PDF/Bull\%2020062-ENG.pdf [consulted 12 November 2007].
} 
Table I. Equine influenza virus (EIV) strains used in this study.

\begin{tabular}{llll}
\hline EIV strain & Subtype & H3N8 Sublineage & Use in the study \\
\hline A/eq/Newmarket/77 & H7N7 & na & Vaccination \\
A/eq/Sussex/89 & H3N8 & European & IFN $\gamma$ assay \\
A/eq/Borlänge/91 & H3N8 & European & Vaccination/SRH assay \\
A/eq/Kentucky/98 & H3N8 & American & Vaccination/SRH assay \\
A/eq/SouthAfrica/4/03 & H3N8 & American & Challenge/SRH assay \\
\hline
\end{tabular}

na $=$ Not applicable. $\mathrm{SRH}=$ Single radial haemolysis.

strains A/eq/Borlänge/91, A/eq/Kentucky/98, and $\mathrm{A} / \mathrm{eq} / \mathrm{South}$ Africa/4/03 were used in the single radial haemolysis (SRH) assay. EIV strain A/eq/South Africa/4/03 was used for experimental infection of ponies. Viruses were all grown in embryonated hen's eggs. The virions were concentrated from allantoic fluid by centrifugation for $3 \mathrm{~h}$ at $54000 \times g$ and $4{ }^{\circ} \mathrm{C}$ in an LKB RP19 rotor (LKB, Bromma, Sweden) and further purified through a 15/30/60\% (wt/vol) discontinuous sucrose cushion in phosphate-buffered saline (PBS) for $2 \mathrm{~h}$ at $72000 \times g$ and $4^{\circ} \mathrm{C}$ (LKB 28SA rotor, $\mathrm{LKB}$ ). The virions were harvested from the $30 / 60 \%$ sucrose cushions interface, re-suspended in PBS and pelleted by centrifugation for $2.5 \mathrm{~h}$ at $90000 \times g$ and $4{ }^{\circ} \mathrm{C}$ (LKB 28SA rotor, LKB). EIV titre was measured by haemagglutination assay. The HA titre was taken as the last virus dilution giving at least $50 \%$ haemagglutination of an equal volume $(25 \mu \mathrm{L})$ of a $1 \%$ suspension of chicken erythrocytes and expressed as HA units/mL. Equine herpesvirus-1 strain Ab4/14 was used as a control for the IFN $\gamma$ assay at specified $50 \%$ tissue culture infectious dose $\left(\mathrm{TCID}_{50}\right)$ defined on an equine embryonic lung (EEL) cell line.

\subsection{Experimental animals}

Ten Welsh mountain ponies (yearlings), seronegative and unprimed for EIV, were used. Only healthy ponies in good clinical condition as ascertained by a qualified veterinary surgeon were included in the study. All work involving experimental ponies was performed under a Home Office Project Licence and was approved by the Animal Health Trust's Ethical Review Committee. All ponies were fully recovered at the end of the study.

\subsection{Vaccine, vaccination protocol, and challenge infection}

The EQUIPTM $\mathrm{F}$ ISCOM vaccine (Schering Plough Animal Health, Uxbridge, UK) containing
$10 \mu \mathrm{g} \mathrm{A}$ eq/Newmarket/77 (H7N7), $20 \mu \mathrm{g} \mathrm{A/eq/}$ Borlänge/91 (H3N8), and $20 \mu \mathrm{g} \mathrm{A}$ /eq/Kentucky/98 (H3N8) was used at $2 \mathrm{~mL}$ per dose. The ponies were randomly assigned to two groups (A and B) with six ponies in group $\mathrm{A}$ and four in group B. Vaccinates (group A) received two doses of EQUIPTMF ISCOM given six weeks apart (days 0 and 42). Animals in group B were not vaccinated. After each vaccination, ponies were examined during three days for the occurrence of local and/or systemic reactions. Temperatures $>38.8^{\circ} \mathrm{C}$ were considered abnormal. No local reactions and no pyrexia were observed after the first or second vaccinations (data not shown). All ponies were challenged on day 56 (14 days after the second immunisation) by exposure to an aerosol generated from $20 \mathrm{~mL}$ of allantoic fluid diluted in PBS containing $10^{6.66} 50 \%$ egg infectious doses $\left(\mathrm{EID}_{50}\right)$ of influenza A/eq/South Africa/4/03 (representative strain of recently circulating equine influenza virus from the American lineage) using a nebuliser (model ULTRA-NEB ${ }^{\circledR}$ 2000; DeVillbiss Health Care, Somerset, PA, USA).

\subsection{Clinical signs of disease and virus excretion}

Clinical signs associated with equine influenza, including nasal discharge, coughing, and dyspnoea were recorded daily for each pony from day 56 to day 70 . The signs were scored using a standardised protocol [7]. On the same days, rectal temperatures were measured. Temperatures $>38.8^{\circ} \mathrm{C}$ were considered pyretic. The ponies used in these studies are generally not used to manipulations (e.g. bleeding, nasal swabs, etc.) and the resulting "excitation" often increases basal temperature. To avoid false pyrexia due to excitation, $38.9^{\circ} \mathrm{C}$ is the reference pyretic temperature used at the Animal Health Trust. Nasal swabs were taken from each pony from the day after challenge (day 1 post challenge) through to day 10 . Infectious virus was titrated in embryonated hens' eggs 
and expressed as $\mathrm{EID}_{50}$ per $\mathrm{mL}$ of swab extract as described previously [15]. Ponies developing apparent clinical signs were treated against secondary bacterial infection with trimethoprim potentiated sulphonamide antibiotic (Trimediazine; Fort Dodge Animal Health, Southampton, UK) paste administered orally on days 5 to 10 (inclusive) post challenge infection. Each treated pony was given a dose appropriate to a $250 \mathrm{~kg}$ pony.

\subsection{Serological methods}

Blood samples for serological analysis were taken on days $0,7,14,42,49,56$, and 70 and assayed for antibody by SRH [38] with A/eq/Borlänge/91, A/eq/Kentucky/98, and A/eq/South Africa/4/03 as representative antigens. The titres of antibody were expressed as the area of haemolysis $\left(\mathrm{mm}^{2}\right)$. An increase of $35 \mathrm{~mm}^{2}$ or $50 \%$ in the area of the zone of haemolysis was regarded as a significant rise in antibody and indicative of infection if measured between pre- (day 56) and post- (day 70) challenge.

\subsection{Measure of IFN $\gamma$ synthesising cells}

Heparinised blood samples were taken on days 0,56 , and 70. PBMC were purified from heparinised blood by centrifugation on FicollHypaque (Amersham Biosciences, Uppsala, Sweden). EIV-specific effectors were derived from fresh PBMC co-cultured with EIV-infected PBMCs to increase the frequency of EIV-specific T cells, as previously described [20]. Briefly, $5 \times 10^{7} \mathrm{PBMC}$ were treated with trypsin $(\mathrm{BDH}$, Poole, $\mathrm{UK})$ at $0.125 \mu \mathrm{g} / \mathrm{mL}$ for $1 \mathrm{~h}$ at $37^{\circ} \mathrm{C}$ prior to being infected with EIV as follows: $5 \times 10^{7}$ PBMC were distributed in ten wells of a 96-well U-bottomed plate $\left(5 \times 10^{6}\right.$ PBMC per well) and centrifuged $(7 \mathrm{~min}$, $175 \times g)$. The supernatant was discarded and replaced with $50 \mu \mathrm{L}$ amplification medium containing $1 \times 10^{4} \mathrm{HA}$ units $/ \mathrm{mL}$ of $\mathrm{A} / \mathrm{eq} / \mathrm{Sussex} / 89$ and trypsin at $0.125 \mu \mathrm{g} / \mathrm{mL}$. Amplification medium consisted of $\mathrm{AIMV}^{\circledR}\left(50 \%\right.$; GIBCO ${ }^{\mathrm{TM}}$, Invitrogen Corp., Paisley, UK) and RPMI 1640 (45\%) supplemented with $2 \mathrm{mM}$ L-glutamine, $55 \mu \mathrm{M}$ 2-mercaptoethanol, $0.05 \mathrm{mM}$ NEAA, $0.5 \mathrm{mM}$ sodium pyruvate, $50 \mu \mathrm{g} / \mathrm{mL}$ gentamycin, $5 \%$ foetal calf serum, and $5 \%$ heat-inactivated equine serum (all supplied by Sigma Ltd, Poole, UK). PBMC were incubated at $37^{\circ} \mathrm{C}$ for $1 \mathrm{~h}$. Infected PBMC were washed once $(7 \mathrm{~min}, 175 \times g)$ and then cultivated in amplification medium, in the same flask as autologous uninfected PBMC $\left(5 \times 10^{7} \mathrm{PBMC}\right)$, in the presence of $5 \%$ heat treated horse serum (Sigma Ltd.). After seven days of culture, effector cells were purified by centrifugation on Fycoll-Hypaque and washed three times in PBS prior to stimulation. IFN $\gamma$ synthesis was measured as previously described $[19,22]$. A total of $10^{6}$ fresh PBMC were stimulated in vitro with $\mathrm{A} / \mathrm{eq} / \mathrm{Sussex} / 89(\mathrm{H} 3 \mathrm{~N} 8)$ at $10^{3} \mathrm{HA}$ unit/mL. Brefeldin A (BFA; BD GolgiPlug ${ }^{\mathrm{TM}}$, BD Biosciences, Oxford, UK) was added $4 \mathrm{~h}$ after the stimulation $(1 \mu \mathrm{L} / \mathrm{mL}$ final concentration according to the manufacturer's recommendation). After overnight incubation, expression of CD5 or CD8 was determined using the mouse anti-equine CD5 antibody (clone HB19a, IgG2a isotype; VMRD, Pullman, USA) or the mouse anti-equine CD8 $\alpha$ antibody (clone 73/6.9.1, IgG3 isotype; VMRD). Fluorescein isothiocyanate (FITC)-conjuguated rabbit anti-mouse IgG2a (Serotec Ltd; Oxford, UK) or FITC-conjuguated goat anti-mouse IgG3 (Southern Biotechnology, Cambridge, UK) were used as secondary antibodies. Cells were fixed in $3 \%$ formaldehyde in PBS v/v prior to detection of equine IFN $\gamma$ by intra-cellular cytokine staining (ICC) using a biotinylated antibody specific for equine IFN $\gamma$ (clone CC302, Serotec Ltd) [19] and streptavidin-rhodamine phycoerythrin (RPE) (Serotec Ltd) in permeabilisation buffer (PBS with $0.5 \%$ bovine serum albumin and $0.20 \%$ saponin, Sigma Ltd). For single colour staining to detect intracellular IFN $\gamma$, unbiotinylated clone CC302 antibody and FITC-conjuguated goat anti-mouse IgG antibody (Stratech Scientific Ltd, Newmarket, UK) were used. IFN $\gamma$ detection was performed in duplicate or triplicate. The percentage of virus specific IFN $\gamma$ synthesis was calculated according to the formula (\% virus stimulated IFN $\gamma$ synthesis)-(\% medium stimulated IFN $\gamma$ synthesis $)$. $\mathrm{T}$ lymphocytes $\mathrm{CD} 8 \alpha^{\text {neg }}$ or $\mathrm{CD} 8 \alpha^{\text {high }}$ phenotypes were defined using none activated PBMC purified from an unvaccinated and uninfected pony.

\subsection{Statistical analysis}

Statistical analyses were performed with StatView (version 4.5) or the StatGraphics Plus ${ }^{\circledR}$ program for Windows (Statistical Graphics Corporation, Orlean, VA, USA). Student's t-test was used to test significance of SRH antibody response and IFN $\gamma$ data between the vaccinated and unvaccinated 
groups (Tuckey HSD or Boneferroni procedure with a confidence interval of 95\%). The level of significance was set at $p$-value $<0.05$. If variances between each group were not homogenous ( $p$-value $<0.05)$, data were $\log$ transformed to allow $t$-test.

\section{RESULTS}

\subsection{SRH antibody response}

\subsubsection{After vaccination}

None of the control ponies (group B) developed an antibody response prior to challenge infection with EIV (Fig. 1 and Tab. II). All of the vaccinated ponies responded to vaccination and developed an SRH antibody response measured with A/eq/Kentucky/98 and $\mathrm{A} / \mathrm{eq} / \mathrm{South}$ Africa/4/03 antigens. One of the six vaccinates (\#A2) did not possess SRH antibodies detectable with A/eq/Borlänge/91 antigens after the first vaccination. By day 49 (7 days after V2), all vaccinated ponies showed an antibody response to vaccination measurable with all three virus strains. The mean SRH results in the vaccine group at the time of challenge (14 days after the second vaccination) obtained with A/eq/South Africa/4/03 antigens (137 \pm $24 \mathrm{~mm}^{2}$ ) were equivalent to those obtained with A/eq/Kentucky/98 or A/eq/Borlänge/91 antigens $\left(133 \pm 19\right.$ and $123 \pm 23 \mathrm{~mm}^{2}$, respectively). Two of the vaccinated ponies (\#A2 and \#A6) had relatively low SRH antibody levels on day 56, one pony (\#A2) was below the $120-150 \mathrm{~mm}^{2}$ cut-off thought to be required to be assured of protection against clinical signs of disease and virus shedding after challenge with a strain homologous or related to the vaccine strain $[14,16]$.

\subsubsection{After challenge infection with $\mathrm{EIV}$}

All control ponies had seroconverted against all three strains tested at 14 days post challenge (Fig. 1 and Tab. II), the highest individual response recorded $\left(176.7 \mathrm{~mm}^{2}\right)$ was against the challenge virus $\mathrm{A} / \mathrm{eq} / \mathrm{South}$ Africa/4/03 but the mean was highest to A/eq/Kentucky/98. Only one vaccinated pony
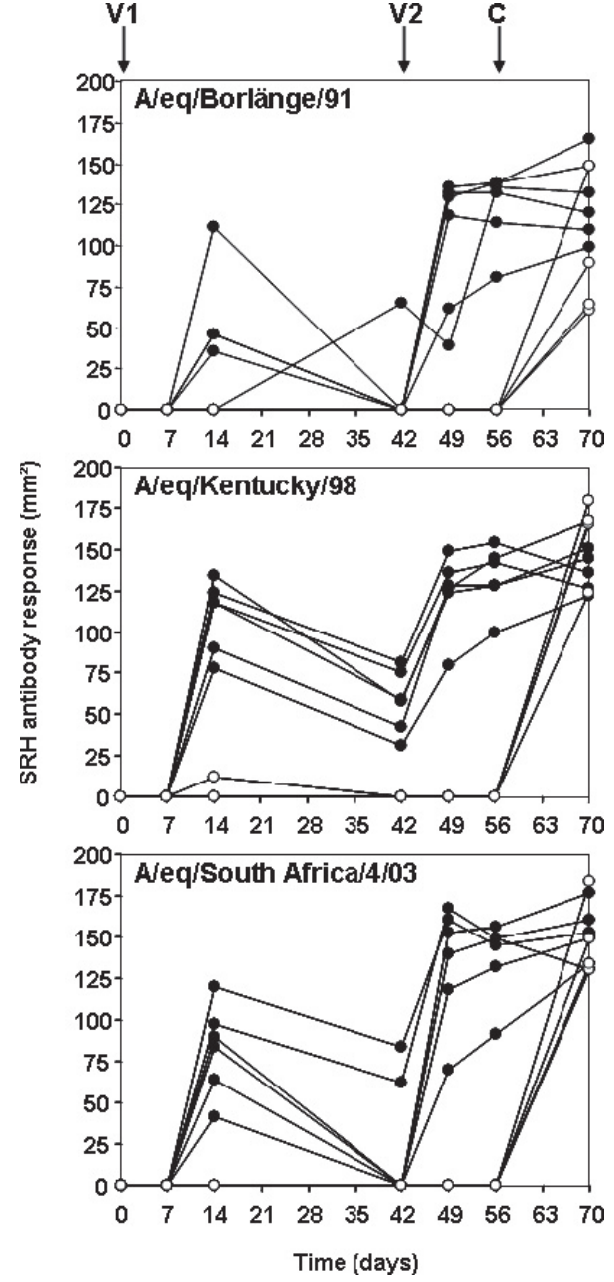

Figure 1. Kinetics of single radial haemolysis (SRH) antibody responses to $\mathrm{A} / \mathrm{eq} / \mathrm{Borlänge/91,}$ $\mathrm{A} / \mathrm{eq} / \mathrm{Kentucky} / 98$, and A/eq/South Africa/4/03 reference antigens in vaccinated ponies (closed circles) and control ponies (open circle). $\mathrm{V} 1=$ first vaccination; $\mathrm{V} 2=$ second vaccination; $\mathrm{C}=$ experimental challenge with $\mathrm{A} / \mathrm{eq} / \mathrm{South}$ Africa/4/03.

(\#A2), which had the lowest pre-challenge antibody level, demonstrated a significant antibody increase $\left(>35 \mathrm{~mm}^{2}\right)$ post challenge. This significant increase was only detected using the challenge strain A/eq/South Africa/4/03 as antigen. 
Table II. Mean titres of single radial haemolysis antibody.

\begin{tabular}{cllcccccc}
\hline & Antigens & \multicolumn{7}{c}{ Day } \\
\cline { 3 - 9 } & & $\mathrm{V} 1$ & $\mathrm{~V} 1+7$ & $\mathrm{~V} 1+14$ & $\mathrm{~V} 2$ & $\mathrm{~V} 2+7$ & $\mathrm{~V} 2+14 / \mathrm{C}$ & $\mathrm{C}+14$ \\
\cline { 2 - 9 } & & 0 & 7 & 14 & 42 & 49 & 56 & 70 \\
\hline Group A (vaccinates) & $\mathrm{B} / 91$ & 0 & 0 & $40 \pm 41$ & $11 \pm 27$ & $103 \pm 41$ & $123 \pm 23$ & $129 \pm 25$ \\
$\quad(n=6)$ & $\mathrm{K} / 98$ & 0 & 0 & $110 \pm 22$ & $58 \pm 19$ & $124 \pm 24$ & $133 \pm 19$ & $141 \pm 17$ \\
& $\mathrm{SA} / 4 / 03$ & 0 & 0 & $82 \pm 27$ & $24 \pm 38$ & $135 \pm 36$ & $137 \pm 24$ & $150 \pm 17$ \\
Group B (controls) & $\mathrm{B} / 91$ & 0 & 0 & 0 & 0 & 0 & 0 & $91 \pm 41$ \\
$\quad(n=4)$ & $\mathrm{K} / 98$ & 0 & 0 & $3 \pm 6$ & 0 & 0 & 0 & $159 \pm 24$ \\
& $\mathrm{SA} / 4 / 03$ & 0 & 0 & 0 & 0 & 0 & 0 & $149 \pm 25$ \\
\hline
\end{tabular}

$\mathrm{B} / 91=\mathrm{A} / \mathrm{eq} /$ Borlänge/91; K/98 = A/eq/Kentucky/98; SA/4/03 = A/eq/South Africa/4/03; V = vaccination; $\mathrm{C}=$ challenge infection.

\subsection{EIV-specific IFN $\gamma$ response}

\subsubsection{Response to vaccination and experimental infection with $\mathrm{EIV}$}

PBMC were purified on the day of the first vaccination (V1), immediately prior to in vivo challenge infection with A/eq/South Africa/4/03 (i.e. 14 days after the second vaccination) and 14 days after challenge infection. PBMC were culture amplified with EIV A/eq/Sussex/89 for seven days prior to overnight stimulation with either EIV A/eq/Sussex/89 strain or EHV-1 and IFN $\gamma$ ICC staining. As shown in Figure 2, the percentage of EIV-specific IFN $\gamma^{+}$PBL was low in both groups at V1 $(0.22 \% \pm 0.3$ and $0.03 \% \pm 0.2$ for groups A and B, respectively). Two weeks after the second vaccination, the percentage of EIV-specific IFN $\gamma^{+}$PBL strongly increased in vaccinates $(4.8 \% \pm 3.9)$ when compared with percentages measured in control ponies, which remained at a background level $(0.48 \% \pm 0.5)$. Two weeks after challenge infection with EIV, the percentage of EIV-specific IFN $\gamma^{+}$PBL increased in control ponies $(2.38 \% \pm 1.6)$ and remained high in vaccinates $(3.75 \% \pm 1.2)$. No increase of virus-specific IFN $\gamma^{+}$PBL was measured at any of the time points studied when PBMC were stimulated overnight with EHV-1, indicating that the response was specific to EIV.

\subsubsection{Phenotype of EIV-specific IFN $\gamma^{+}$PBL}

The phenotype of EIV-specific IFN $\gamma^{+}$ PBL induced by vaccination with the EIVISCOM vaccine was studied two weeks after V2. As illustrated in Figure 2B, the majority of EIV-specific IFN $\gamma^{+} \mathrm{PBL}$ were $\mathrm{CD}^{+} \mathrm{T}$ lymphocytes $(95.2 \% \pm 2)$ and the percentage of EIV-specific $\mathrm{CD}^{+} \mathrm{IFN}^{+} \mathrm{PBL}$ was significantly different between groups A (vaccinates) and $\mathrm{B}$ (control) ( $p$-value $=$ 0.01). Lymphocytes of the CD8 $\alpha$ phenotype represented only $19.2 \% \pm 8.9$ of the total EIV-specific IFN $\gamma^{+}$cell population (Fig. 2C). Four of the six vaccinates showed increased percentage of $\mathrm{CD} 8 \alpha^{+} \mathrm{IFN} \gamma^{+} \mathrm{PBL}$ when compared with the group of control ponies. After challenge infection with A/eq/South Africa/4/03, the phenotype of EIV-specific IFN $\gamma^{+}$PBL was similar between groups. EIV-specific IFN $\gamma^{+}$PBL were $\mathrm{CD}^{+}$in the majority $(95.5 \% \pm 4$ and $97.1 \% \pm 4.5$ for groups A and B, respectively), with $28.5 \% \pm$ 8.2 and $23.8 \% \pm 10.6$ of cells having a CD8 $\alpha^{+}$ phenotype (groups A and B, respectively).

\subsection{Expression of $\mathrm{CD8} \alpha$ molecule by PBL}

Interestingly, expression of the CD8 $\alpha$ molecule in the overall CD8 $\alpha^{+}$cell population was affected by vaccination. As shown in Figure 3, the expression level of the CD8 $\alpha$ 
A
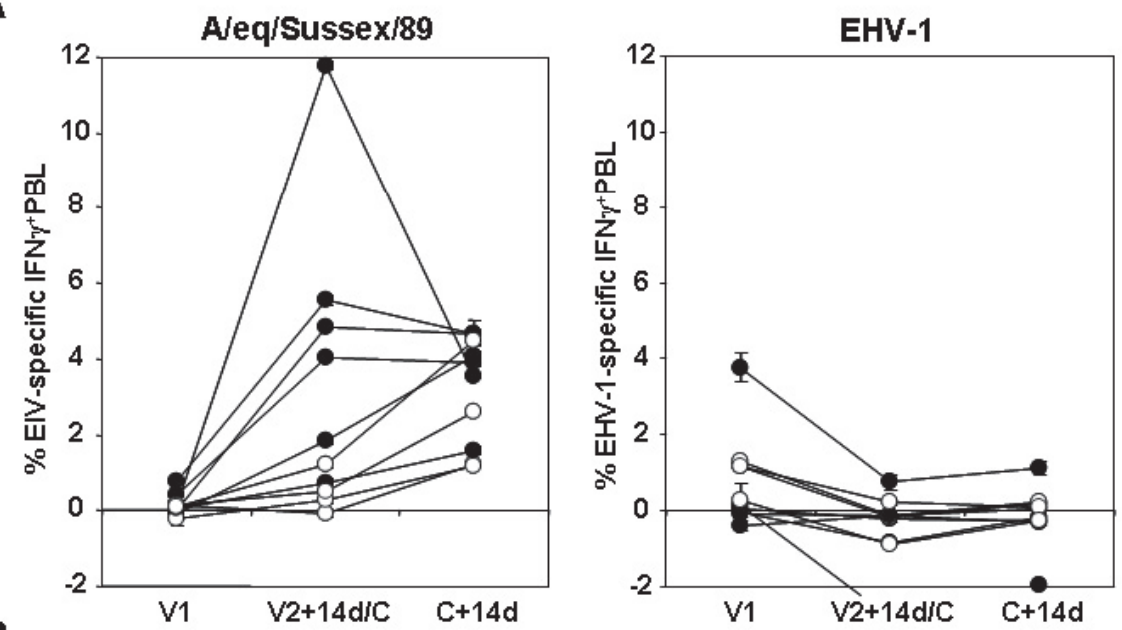

$B$
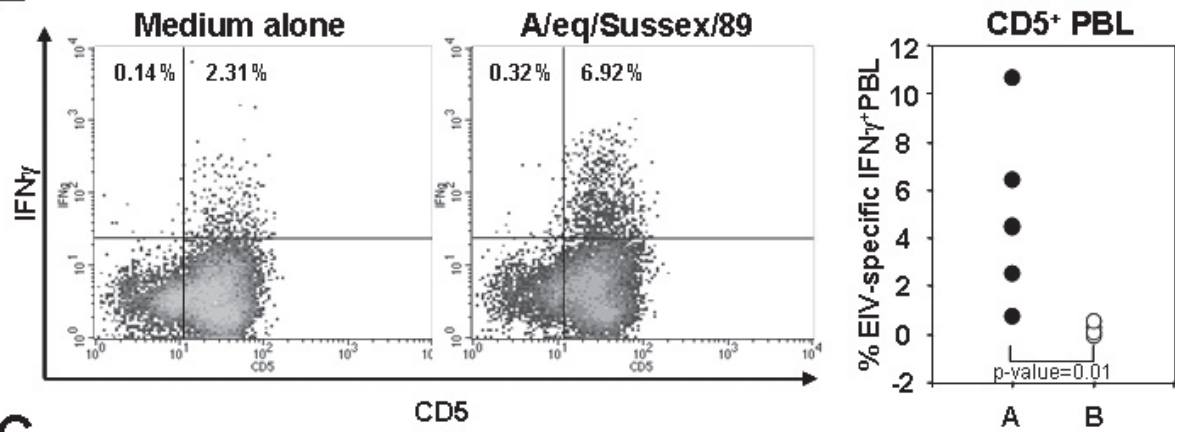

Q
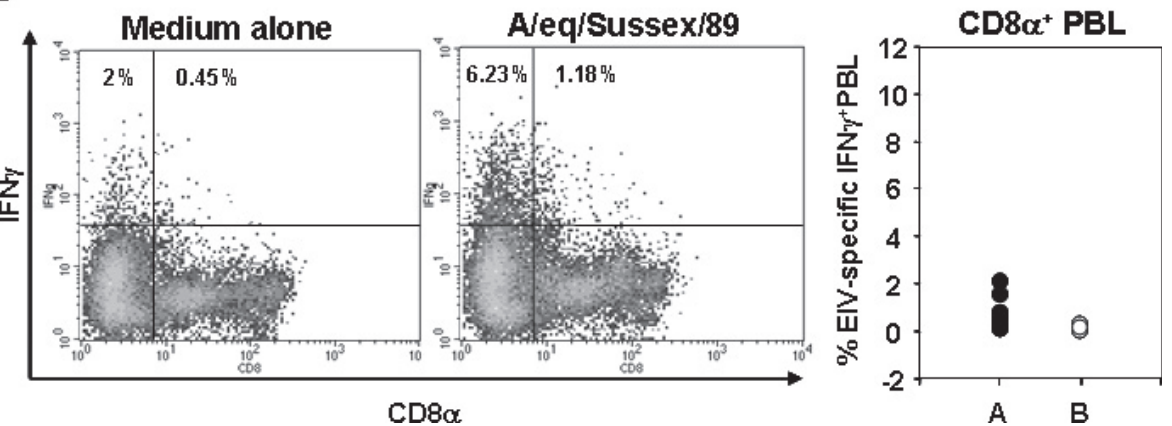

Figure 2. Equine influenza virus (EIV)-specific IFN $\gamma$ response: (A) Kinetics of virus-specific IFN $\gamma^{+} \mathrm{PBL}$ purified from control ponies (open circles) or vaccinates (closed circle), culture amplified and stimulated overnight with either A/eq/Sussex/89 or EHV-1 as a control of virus specificity. V1 = first vaccination; $\mathrm{C}=$ experimental challenge with A/eq/South Africa/4/03. CD5 (B) and CD8 $\alpha$ (C) phenotype of EIVspecific IFN $\gamma^{+}$PBL, 2 weeks after the second vaccination. Typical CD5- or CD8 $\alpha$-IFN $\gamma$ double staining of PBL from pony \#A2, culture amplified and stimulated overnight with medium alone or A/eq/Sussex/89 and comparison of the percentage of EIV-specific $\mathrm{CD}^{+}$or $\mathrm{CD} 8 \alpha^{+}$IFN $\gamma^{+} \mathrm{PBL}$ in vaccinated (group A) and unvaccinated ponies (group B). 
A

CD8 $\alpha$ expression by CD $8 \alpha^{+}$PBL: prechallenge
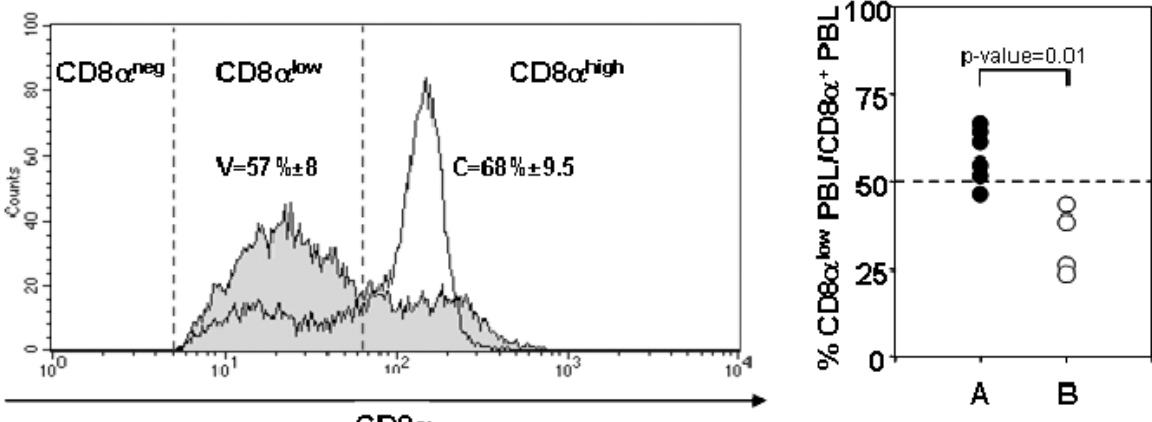

B
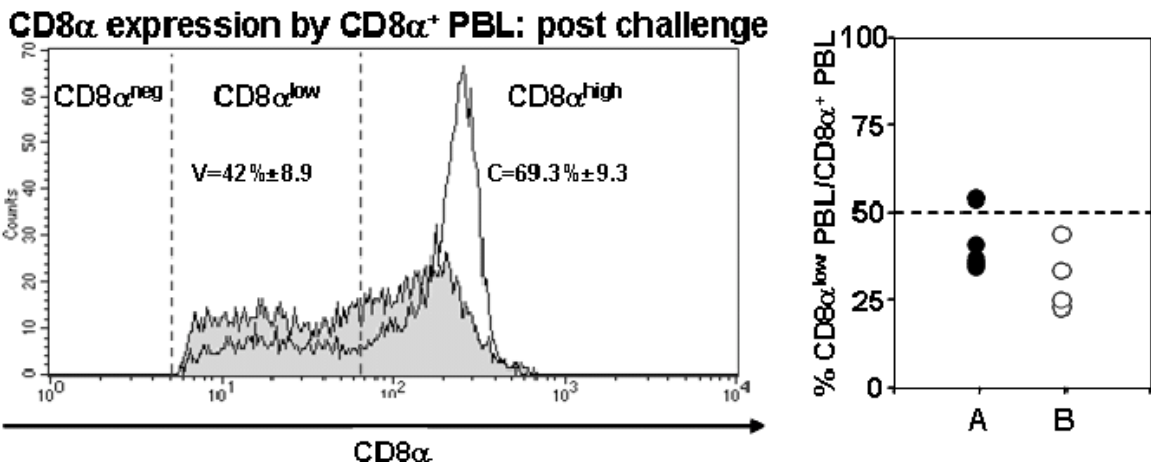

Figure 3. Expression of the CD8 $\alpha$ molecule by PBL. Overlay histogram of CD $8 \alpha$ molecule expression by $\mathrm{CD} 8 \alpha^{+}$PBL purified from ponies prior to (A) and after challenge infection with a/eq/South Africa/4/03 (B). Histograms are representative of controls (white; C) or vaccinates (grey; V). The mean proportion of $\mathrm{CD} 8 \alpha^{\text {low }}$ or $\mathrm{CD} 8 \alpha^{\text {high }}$ inside $\mathrm{CD} 8 \alpha^{+} \mathrm{PBL}$ is calculated for vaccinates and controls, respectively. The proportion of $\mathrm{CD} 8 \alpha^{\text {low }} \mathrm{PBL}$ inside the $\mathrm{CD} 8 \alpha^{+}$cell population is calculated for each ponies and compared between groups.

molecule was predominantly low $\left(\mathrm{CD} 8 \alpha^{\text {low }}\right.$, $57 \% \pm 8)$ in $\mathrm{CD} 8 \alpha^{+} \mathrm{PBL}$ purified from vaccinated ponies (group A), two weeks after the second administration of the EIVISCOM vaccine. In contrast, $\mathrm{CD} 8 \alpha^{+} \mathrm{PBL}$ purified from control ponies were mostly $\mathrm{CD} 8 \alpha^{\text {high }}(68 \% \pm 9.5)$, as is usually observed in ponies. This difference of CD8 $\alpha$ molecule expression by PBL between groups was statistically significant $(p$-value $=0.01)$. Two weeks after experimental infection with EIV, the percentage of $\mathrm{CD} 8 \alpha^{\text {high }} \mathrm{PBL}$ remained unchanged in control ponies $(69.3 \% \pm 9.3)$. The CD8 $\alpha$ phenotype shifted from low to high in the vaccinated group $(58.2 \% \pm 8.9$ of CD8 $\alpha^{\text {high }}$ PBL) when compared with the pre-challenge infection level $(42.9 \% \pm 7.9$ of $\mathrm{CD} 8 \alpha^{\text {high }} \mathrm{PBL}$ at $\mathrm{V} 2+2$ weeks).

\subsection{Clinical signs of disease induced by EIV}

\subsubsection{Coughing and dyspnoea}

None of the vaccinated ponies (group A) were observed to cough throughout the challenge period (Tab. III). All of the control ponies (group B) were observed to cough for a total of six to nine days during the first ten days post challenge (mean 7.2 days). Furthermore, laboured breathing was observed in all four of the control ponies between days 2 and 10 post challenge. 
Table III. Clinical signs of disease and virus shedding after experimental infection with A/eq/South Africa/4/03.

\begin{tabular}{|c|c|c|c|c|c|c|c|c|c|c|c|c|c|}
\hline & \multirow[t]{2}{*}{ Signs } & \multicolumn{10}{|c|}{ Day pre/post experimental challenge } & \multirow[b]{2}{*}{10} & \multirow[b]{2}{*}{ Total } \\
\hline & & $\overline{\mathrm{C}}$ & 1 & 2 & 3 & 4 & 5 & 6 & 7 & 8 & 9 & & \\
\hline \multirow{6}{*}{$\begin{array}{l}\text { Group A } \\
\quad \text { (vaccinates) } \\
(n=6)\end{array}$} & Cough & 0 & 0 & 0 & 0 & 0 & 0 & 0 & 0 & 0 & 0 & 0 & 0 \\
\hline & Dysponea & 0 & 0 & 0 & 0 & 0 & 0 & 0 & 0 & 0 & 0 & 0 & 0 \\
\hline & $\mathrm{ND}^{1}$ & 1 & 2 & 1 & 2 & 2 & 3 & 4 & 2 & 5 & 7 & 2 & 31 \\
\hline & $\mathrm{BT}^{2}$ & 0 & 0 & 0 & 0 & 0 & 0 & 0 & 0 & 0 & 0 & 0 & 0 \\
\hline & Total & 1 & 2 & 1 & 2 & 2 & 3 & 4 & 2 & 5 & 7 & 2 & 31 \\
\hline & $\mathrm{VS}^{3}$ & 0 & 0 & 0 & 0 & 0 & 0 & 0 & 0 & 0 & 0 & 0 & na \\
\hline \multirow{6}{*}{$\begin{array}{l}\text { Group B } \\
\quad(\text { controls }) \\
(n=4)\end{array}$} & Cough & 0 & 0 & 0 & 6 & 8 & 6 & 4 & 3 & 4 & 5 & 3 & 40 \\
\hline & Dysponea & 0 & 0 & 1 & 1 & 3 & 4 & 2 & 2 & 2 & 1 & 1 & 17 \\
\hline & $\mathrm{ND}^{1}$ & 3 & 4 & 5 & 4 & 9 & 14 & 8 & 3 & 5 & 6 & 3 & 64 \\
\hline & $\mathrm{BT}^{2}$ & 0 & 0 & 0 & 3 & 3 & 3 & 1 & 0 & 1 & 0 & 0 & 11 \\
\hline & Total & 3 & 4 & 6 & 14 & 23 & 27 & 15 & 8 & 12 & 12 & 7 & 132 \\
\hline & $\mathrm{VS}^{3}$ & 0 & 0 & 0 & 0 & $1.6 \pm 1.2$ & $0.3 \pm 0.5$ & $0.5 \pm 0.6$ & 0 & 0 & 0 & 0 & na \\
\hline
\end{tabular}

${ }^{1}$ Nasal discharge.

2 Body temperature.

3 Virus shedding.

na $=$ Not applicable; $\mathrm{C}=$ challenge infection.

\subsubsection{Nasal discharges}

One pony in group A and two ponies in group B presented nasal discharges on the day prior to challenge infection (Tab. III). After infection, nasal discharges were noted in all four of the control ponies (group B) and all had extremely evident mucopurulent discharge at some point between days 4 and 6 post challenge. In Group A, five out of the six vaccinated ponies were observed to have serous nasal discharge on at least one day, but mucopurulent discharge was only observed in three ponies and for one day only.

\subsubsection{Temperature}

Three of the four control ponies (group B) developed pyrexia (Fig. 4). All three were pyretic on three consecutive days (days 3 to 5). Two animals each had an additional day of pyrexia (one on day 6 and the other on day 8). The mean temperature was above $38.8^{\circ} \mathrm{C}$ on days 3 to 5 for Group B. None of the ponies in Group A developed a pyretic temperature.

\subsubsection{Total clinical scores}

Total clinical scores for groups A and B were 31 and 132, respectively, with a mean of 5.2 and 33 (Tab. III). All four control ponies (group B) had high clinical scores post challenge and these were derived from pyrexia (with the exception of pony \#B1), coughing, dyspnoea, and nasal discharges for all four ponies. The total clinical scores in group A were entirely derived from observed nasal discharges. No clinical signs were recorded during the 10-day post challenge period for one pony (\#A1) in Group A.

\subsection{Virus shedding after challenge infection with EIV}

There was no detectable virus shedding in the vaccinated group from the day of challenge to ten days post challenge infection (Tab. III). All control ponies shed virus after challenge infection. Virus shedding was detected on day 4 in three of the four ponies. One pony was shown to be shedding virus on both days 4 


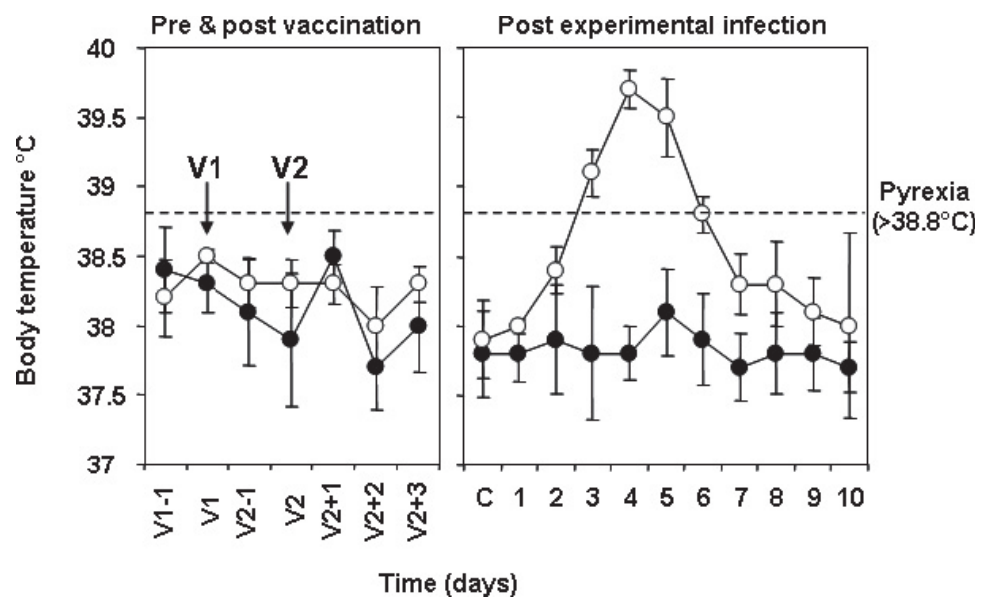

Figure 4. Mean of rectal temperatures for control pony group (open circle) and vaccinated pony group (closed circle) taken pre- and post-vaccination (V1 and V2) and for ten consecutive days after experimental challenge with A/eq/South Africa/4/03 (C). Temperatures $>38.8^{\circ} \mathrm{C}$ (dotted line) were considered pyretic.

and 5. Pony \#B1 only started shedding virus at day 6 . These levels of virus shedding were lower than anticipated; therefore virus titration was repeated on duplicate aliquots of nasal swab extracts that had not been previously thawed and were found to be in accordance with those reported here (data not shown).

\section{DISCUSSION}

ISCOM-based vaccines for EIV are part of a whole generation of vaccines commercialised during the last decade (reviewed in [18]), which are designed to present antigen via both MHC class I and II molecules and subsequently to stimulate an immune response not restricted to highly virus-specific antibodies. A broader immunity induced by vaccination, involving both humoral and cellmediated immunity, is predicted to improve protection and recovery in the case of significant mismatch between the vaccine EIV strain and field isolates. Previous studies of EIV-ISCOM vaccination in ponies were generally limited to measurement of the antibody response ${ }^{4}[15,16,33]$. Concerning this particular commercialised EIV ISCOM

\footnotetext{
${ }^{4}$ Hannant D., Jessett D.M., O’Neill T., Livesay G.J., Mumford J.A., Cellular immune responses
}

vaccine, protection was challenged with a strain of EIV isolated more than a decade ago, namely A/eq/Newmarket/1/93 [4,5]. The present study has broadened the investigation of immune responses induced by vaccination by measuring EIV-specific IFN $\gamma^{+} \mathrm{PBL}$ in peripheral blood, which is a new marker of type-1 immunity in the horse, in addition to the classical SRH assay for antibody levels. Vaccinated ponies were also challenged with A/eq/SouthAfrica/4/03 to assess crossprotection against this recent strain of EIV.

The EIV-ISCOM vaccine (EQUIPTM F; Schering Plough Animal Health) was well tolerated and there were no local reaction to its administration. As expected, high levels of SRH antibody specific to EIV strains contained in the vaccine (A/eq/Borlänge/91 and $\mathrm{A} / \mathrm{eq} /$ Kentucky/98) were detected after two immunisations. SRH antibody cross-reacting with the challenge strain (A/eq/South Africa/ 4/03) was also measured after vaccination

stimulated by inactivated virus vaccines and infection with equine influenza virus (H3N8), in: Equine Infectious Diseases VII, Proceedings of Seventh International Conference on Equine Infectious Diseases, Nakajima H., Plowright W. (Eds.), R \& W Publications Ltd, Newmarket, UK, 1994, pp. 169-174.

Page 10 of 14 (page number not for citation purpose) 
with values around the threshold thought to protect against infection with EIV $[14,16]$. In control ponies, SRH antibody levels were almost undetectable throughout the sampling period from the first vaccination to the day of challenge infection, suggesting that no field infection of equine influenza occurred during this period. After challenge infection with A/eq/SouthAfrica/4/03, all four unvaccinated ponies developed clinical signs of infection with protracted coughing being particularly noteworthy, although only three developed pyrexia. Nasal discharge was not regarded as a reliable sign of infection as some ponies entered the challenge phase of the study with nasal discharges evident. All four unvaccinated ponies shed virus on one or two days post infection, although the titres of virus shed were low, late in onset and of limited duration. The overall outcome of this challenge infection with $\mathrm{A} / \mathrm{eq} / \mathrm{South}$ Africa/4/03 can be considered as a mild disease. None of the vaccinated ponies coughed at any time during the post challenge observation period and none developed pyrexia nor did the vaccinated ponies shed virus after challenge infection. All four unvaccinated ponies seroconverted after challenge infection whereas only one of the six vaccinated ponies had a significant increase in $\mathrm{SRH}$ antibody using the A/eq/South Africa/4/03 strain after infection. Protection against challenge infection with A/eq/South Africa/4/03 was probably induced by the presence of high level of SRH antibody, leading to sterilising immunity and absence of either clinical signs of disease, virus shedding or even seroconversion in five of the six vaccinated ponies. The sixth pony, who had the lowest level of antibody prior to challenge infection, below levels predicted to protect, did seroconvert after infection but did not develop clinical signs of disease or shed virus.

Vaccines able to stimulate a second line of defence (i.e. CMI) will improve the outcome of disease and recovery after equine influenza if the first line of protection (i.e. neutralising antibody) is insufficient and fails to prevent infection. Until recently, the lack of reliable methods to measure EIV-specific CMI was an obstacle to investigate such responses in horses and therefore also to fully evaluate vaccine efficiency. IFN $\gamma$ is an important mediator of the anti-viral immune response and is involved in several activities such as immuno-modulation, lymphocyte recruitment and activation, and anti-pathogen activity [1]. IFN $\gamma$ promotes CMI both by increasing the presentation of viral peptides by APC and promoting the development of $\mathrm{T}$ helper 1 (Th1) lymphocytes. IFN $\gamma$ therefore is a key factor in the development of a type- 1 response involving CTLs, which ultimately leads to the destruction of virus-infected cells and recovery from infection. EIV-specific IFN $\gamma$ synthesis has recently been characterised and used as a marker of EIV-specific type-1 immunity by our group [20,22]. Greater EIVspecific CTL activity has been associated with an increased percentage of EIV-specific IFN $\gamma^{+}$PBL in ponies experimentally infected with A/eq/Sussex/89 [20]. This marker was applied to assess the immune response induced by the EIV-ISCOM vaccine. Previous studies in horses have not demonstrated any evidence of type-1 immunity stimulation after immunisation with ISCOM-based vaccines against EIV or other equine pathogens such as EHV-1. Indeed, ponies vaccinated with a subunit vaccine containing Quil A as adjuvant failed to induce an influenza-virus specific CTL activity ${ }^{4}$. However, the reduced signs of disease and virus shedding measured in a few ponies vaccinated with an EIV ISCOMbased vaccine and presenting low levels of SRH antibody $\left(<50 \mathrm{~mm}^{2}\right)$ [16] were an indication of defence mecanisms that were not directly linked to a strong antibody response immediately prior to challenge infection. This hypothesis was supported in the current study as an increased frequency of EIV-specific IFN $\gamma^{+}$PBL has been demonstrated for the first time in ponies immunised with an ISCOM-based vaccine when compared with controls. Potential stimulation of EIV-specific CTL by the EIV-ISCOM vaccine and the nature of epitopes targeted will need further investigation.

EIV-specific IFN $\gamma^{+}$cells detected after immunisation were mostly $\mathrm{CD} 5^{+} \mathrm{CD} 8 \alpha^{-} \mathrm{T}$ lymphocytes after culture amplification and 
re-stimulation. These IFN $\gamma^{+}$cells are presumably $\mathrm{CD}^{+} \mathrm{T}$ lymphocytes as expression of the equine CD4 antigen on extrathymic equine $\mathrm{T}$ lymphocytes is mutually exclusive with the CD8 antigen [9]. This result confirms the potent ability of ISCOMs to prime equine Th1 lymphocytes in vivo. A fraction of EIVspecific IFN $\gamma^{+}$cells were $\mathrm{CD}^{+} \mathrm{CD} 8 \alpha^{+} \mathrm{T}$ lymphocytes. In previous studies, both $\mathrm{CD}^{+}$ and $\mathrm{CD}^{+} \mathrm{T}$ lymphocytes have been efficiently antigenically stimulated by murine dendritic cells treated with ISCOM-antigen $[24,25]$. Interestingly, a large proportion of $\mathrm{CD} 8 \alpha^{+} \mathrm{T}$ lymphocytes purified after immunisation and culture amplified one week in the presence of EIV displayed a low expression of the CD8 $\alpha$ molecule at their surface (CD8 ${ }^{\text {low }}$ phenotype). As a co-receptor of the $\mathrm{T}$ cell receptor (TCR), CD8 molecules are internalised and degraded when the TCR is triggered [35] giving rise to a transient $\mathrm{CD} 8^{\text {low }}$ phenotype. The function of CD8 ${ }^{\text {low }} \mathrm{T}$ lymphocytes is controversial. In humans, circulating $\mathrm{T}$ cells expressing low CD8 have been shown to represent a subset of highly activated CD8 T lymphocyte effectors, synthesising IFN $\gamma$ and displaying increased cytotoxicity [34]. This is in contrast to $\mathrm{CD} 8^{\text {low }} \mathrm{T}$ lymphocytes derived from naïve $\mathrm{CD}^{+} \mathrm{T}$ cell cultivated in presence of IL-4, as previously described in mice $[10,11]$. In these studies, CD8 ${ }^{\text {low }} \mathrm{T}$ lymphocytes have been shown to be a stable subpopulation with noncytolytic activity, able to synthesise both IL-4 and IFN $\gamma$ after antigenic stimuli. Reduced cytotoxicity allowed IL-4induced $\mathrm{CD}^{\text {low }}$ cells to provide B cell help, increasing IgM and IgG1 antibody levels [11]. In the current study, the origin and function of the large population of $\mathrm{CD} 8^{\text {low }}$ lymphocytes transiently detected in PBMC purified from vaccinated ponies are unclear. This population could be activated/exhausted lymphocytes resulting from proliferation during the amplification culture of EIV-specific $\mathrm{CD}^{+}$lymphocytes induced by vaccination. However, the hypothesis of a noncytolytic sub-population of $\mathrm{CD}^{+} \mathrm{T}$ lymphocytes cannot be excluded as the synthesis of IL-4 after ISCOM vaccination has been reported in several studies (reviewed in [30]). The recent development of an antibody specific for equine IL-4 will enable further investigation of the CD8 ${ }^{\text {low }}$ cell population [36]. Finally, another possibility is activation of lymphocytes in an antigen independent way through an unidentified bystander effect (e.g. CD8 downregulation has been shown in the absence of specific peptide-MHC complexes, such as after stimulation with superantigens or incubation with monovalent anti-CD3 antibodies [35]).

The EIV strain A/eq/Sussex/89 was the strain of reference for the development of the EIV-specific IFN $\gamma$ assay $[20,22]$ due to high concentration obtained after culture in hens' eggs and purification. This EIV strain was used in the current study to stimulate PBMC in vitro. The importance of strain specificity to the EIV-specific IFN $\gamma$ assay is unknown but currently under investigation. The cross-reactivity of A/eq/Sussex/89 and the vaccine strain A/eq/Borlänge/91 was expected from analysis of results obtained by the hemagglutination-inhibition assay. The similarity in reaction of these strains with monospecific ferret sera indicated that the glycoproteins are of the European sublineage and very closely related antigenically ${ }^{5}$. Glycoproteins from A/eq/Sussex/89 and the challenge strain A/eq/South Africa/4/03 are antigenically and genetically different. However, the EIV-antigens that stimulate CMI are expected to be located on molecules such as nucleoprotein (NP) or matrix (M), as described for human influenza [8]. Amino acids sequences of these molecules are well conserved between EIV strains (data not shown). Therefore, A/eq/Sussex/89 was expected to stimulate in vitro EIV-specific PBL induced by challenge infection with A/eq/South Africa/4/03 to some extent.

In conclusion, the current formulation of

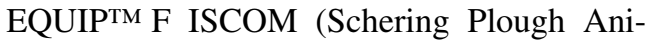
mal Health) gave protection against clinical signs and virus shedding when ponies were challenged with A/eq/South Africa/4/03 two weeks after a second dose of vaccine. This protection is based on both an antibody response,

\footnotetext{
${ }^{5}$ Lewis N., Animal Health Trust, personal communication.
} 
characterised by cross-reactive SRH antibody, and stimulation of EIV-specific IFN $\gamma^{+}$PBL after immunisation. To our knowledge, this demonstration of the stimulation of IFN $\gamma$ synthesis by EIV-specific lymphocytes in vaccinated ponies is the first evidence of ISCOMinduced type- 1 immunity in the horse.

Acknowledgements. The authors would like to gratefully acknowledge Mr F. Montesso, Equine Resources Manager (Animal Health Trust), and his staff, for excellent care of the ponies.

\section{REFERENCES}

[1] Boehm U., Klamp T., Groot M., Howard J.C., Cellular responses to interferon-gamma, Annu. Rev. Immunol. (1997) 15:749-795.

[2] Bungener L., Huckriede A., Wilschut J., Daemen T., Delivery of protein antigens to the immune system by fusion-active virosomes: a comparison with liposomes and ISCOMs, Biosci. Rep. (2002) 22: 323-338.

[3] Cox J.C., Sjolander A., Barr I.G., ISCOMs and other saponin based adjuvants, Adv. Drug Deliv. Rev. (1998) 32:247-271.

[4] Crouch C.F., Daly J., Hannant D., Wilkins J., Francis M.J., Immune responses and protective efficacy in ponies immunised with an equine influenza ISCOM vaccine containing an "American lineage" H3N8 virus, Vaccine (2004) 23:418-425.

[5] Crouch C.F., Daly J., Henley W., Hannant D., Wilkins J., Francis M.J., The use of a systemic prime/mucosal boost strategy with an equine influenza ISCOM vaccine to induce protective immunity in horses, Vet. Immunol. Immunopathol. (2005) 108:345-355.

[6] Daly J.M., Newton J.R., Mumford J.A., Current perspectives on control of equine influenza, Vet. Res. (2004) 35:411-423.

[7] Edlund Toulemonde C., Daly J., Sindle T., Guigal P.M., Audonnet J.C., Minke J.M., Efficacy of a recombinant equine influenza vaccine against challenge with an American lineage H3N8 influenza virus responsible for the 2003 outbreak in the United Kingdom, Vet. Rec. (2005) 156:367-371.

[8] Gotch F., McMichael A., Smith G., Moss B., Identification of viral molecules recognized by influenza-specific human cytotoxic $\mathrm{T}$ lymphocytes, J. Exp. Med. (1987) 165:408-416.

[9] Hannant D., Immunology of horses and donkeys, in: Handbook of vertebrate immunology, Pastoret P.P.,
Griebel P., Bazin H., Govaerts A. (Eds.), Academic Press, London, UK, 1998, pp. 343-371.

[10] Kienzle N., Buttigieg K., Groves P., Kawula T., Kelso A., A clonal culture system demonstrates that IL-4 induces a subpopulation of noncytolytic T cells with low CD8, perforin, and granzyme expression, J. Immunol. (2002) 168:1672-1681.

[11] Kienzle N., Olver S., Buttigieg K., Groves P., Janas M.L., Baz A., Kelso A., Progressive differentiation and commitment of CD8+ T cells to a poorly cytolytic CD8low phenotype in the presence of IL-4, J. Immunol. (2005) 174:2021-2029.

[12] Madic J., Martinovic S., Naglic T., Hajsig D., Cvetnic S., Serological evidence for the presence of A/equine-1 influenza virus in unvaccinated horses in Croatia, Vet. Rec. (1996) 138:68.

[13] Morein B., Bengtsson K.L., Immunomodulation by iscoms, immune stimulating complexes, Methods (1999) 19:94-102.

[14] Mumford J.A., Wood J., Establishing an acceptability threshold for equine influenza vaccines, Dev. Biol. Stand. (1992) 79:137-146.

[15] Mumford J.A., Jessett D.M., Rollinson E.A., Hannant D., Draper M.E., Duration of protective efficacy of equine influenza immunostimulating complex/tetanus vaccines, Vet. Rec. (1994) 134:158-162.

[16] Mumford J.A., Jessett D.M., Dunleavy U., Wood J.L.N., Hannant D., Sundquist B., Cook R.F., Antigenicity and immunogenicity of experimental equine influenza ISCOM vaccines, Vaccine (1994) 12:857-863.

[17] Newton J.R., Daly J.M., Spencer L., Mumford J.A., Description of the outbreak of equine influenza (H3N8) in the United Kingdom in 2003, during which recently vaccinated horses in Newmarket developed respiratory disease, Vet. Rec. (2006) 158:185-192.

[18] Paillot R., Hannant D., Kydd J.H., Daly J.M., Vaccination against equine influenza: quid novi?, Vaccine (2006) 24:4047-4061.

[19] Paillot R., Daly J., Juillard V., Minke J.M., Hannant D., Kydd J.H., Equine interferon gamma synthesis in lymphocytes after in vivo infection and in vitro stimulation with EHV-1, Vaccine (2005) 23:4541-4551.

[20] Paillot R., Kydd J.H., Macrae S., Minke J.M., Hannant D., Daly J.M., New assays to measure equine influenza virus-specific Type 1 immunity in horses, Vaccine (2007) 25:7385-7398.

[21] Paillot R., Ellis S.A., Daly J.M., Audonnet J.C., Minke J.M., Davis-Poynter N., Hannant D., Kydd J.H., Characterisation of CTL and IFN-g synthesis in ponies following vaccination with a NYVAC-based construct 
coding for EHV-1 immediate early gene, followed by challenge infection, Vaccine (2006) 24:1490-1500.

[22] Paillot R., Kydd J.H., Sindle T., Hannant D., Edlund Toulemonde C., Audonnet J.C., Minke J.M., Daly J.M., Antibody and IFN-gamma responses induced by a recombinant canarypox vaccine and challenge infection with equine influenza virus, Vet. Immunol. Immunopathol. (2006) 112:225-233.

[23] Rimmelzwaan G.F., Nieuwkoop N., Brandenburg A., Sutter G., Beyer W.E., Maher D., Bates J., Osterhaus A.D., A randomized, double blind study in young healthy adults comparing cell mediated and humoral immune responses induced by influenza ISCOM vaccines and conventional vaccines, Vaccine (2000) 19:1180-1187.

[24] Robson N.C., Beacock-Sharp H., Donachie A.M., Mowat A.M., The role of antigen-presenting cells and interleukin-12 in the priming of antigen-specific $\mathrm{CD} 4+\mathrm{T}$ cells by immune stimulating complexes, Immunology (2003) 110:95-104.

[25] Robson N.C., Beacock-Sharp H., Donachie A.M., Mowat A.M., Dendritic cell maturation enhances CD8+ T-cell responses to exogenous antigen via a proteasome-independent mechanism of major histocompatibility complex class I loading, Immunology (2003) 109:374-383

[26] Sambhara S., Kurichh A., Miranda R., Tamane A., Arpino R., James O., McGuinness U., Kandil A., Underdown B., Klein M., Burt D., Enhanced immune responses and resistance against infection in aged mice conferred by Flu-ISCOMs vaccine correlate with upregulation of costimulatory molecule CD86, Vaccine (1998) 16: 1698-1704

[27] Sambhara S., Kurichh A., Miranda R., Tumpey T., Rowe T., Renshaw M., Arpino R., Tamane A., Kandil A., James O., Underdown B., Klein M., Katz J., Burt D., Heterosubtypic immunity against human influenza A viruses, including recently emerged avian $\mathrm{H} 5$ and $\mathrm{H} 9$ viruses, induced by FLU-ISCOM vaccine in mice requires both cytotoxic T-lymphocyte and macrophage function, Cell. Immunol. (2001) 211: 143-153.

[28] Sanders M.T., Brown L.E., Deliyannis G., Pearse M.J., ISCOM-based vaccines: the second decade, Immunol. Cell. Biol. (2005) 83:119-128.
[29] Sjolander A., van't Land B., Lovgren Bengtsson K., Iscoms containing purified Quillaja saponins upregulate both Th1-like and Th2-like immune responses, Cell. Immunol. (1997) 177:69-76.

[30] Sjolander A., Cox J.C., Barr I.G., ISCOMs: an adjuvant with multiple functions J. Leukoc. Biol. (1998) 64:713-723.

[31] Sjolander A., Lovgren Bengtsson K., Johansson M., Morein B., Kinetics, localization and isotype profile of antibody responses to immune stimulating complexes (iscoms) containing human influenza virus envelope glycoproteins, Scand. J. Immunol. (1996) 43:164-172.

[32] Sjolander S., Drane D., Davis R., Beezum L., Pearse M., Cox J., Intranasal immunisation with influenza-ISCOM induces strong mucosal as well as systemic antibody and cytotoxic T-lymphocyte responses, Vaccine (2001) 19:4072-4080.

[33] Sundquist B., Lovgren K., Morein B., Influenza virus ISCOMs: antibody response in animals, Vaccine (1988) 6:49-53.

[34] Trautmann A., Ruckert B., Schmid-Grendelmeier P., Niederer E., Brocker E.B., Blaser K., Akdis C.A., Human CD8 $T$ cells of the peripheral blood contain a low CD8 expressing cytotoxic/effector subpopulation, Immunology (2003) 108: 305-312.

[35] Viola A., Salio M., Tuosto L., Linkert S., Acuto O., Lanzavecchia A., Quantitative contribution of CD4 and $\mathrm{CD} 8$ to $\mathrm{T}$ cell antigen receptor serial triggering, J. Exp. Med. (1997) 186:1775-1779.

[36] Wagner B., Hillegas J.M., Antczak D.F., A monoclonal antibody to equine interleukin-4, Vet. Immunol. Immunopathol. (2006) 110:363-367.

[37] Watson D.L., Watson N.A., Fossum C., Lovgren K., Morein B., Interactions between immunestimulating complexes (ISCOMs) and peritoneal mononuclear leucocytes, Microbiol. Immunol. (1992) 36:199-203.

[38] Wood J.M., Mumford J.A., Folkers C., Scott A.M., Schild G.C., Studies with inactivated equine influenza vaccine I. Serological responses of ponies to graded doses of vaccine, J. Hyg. (Lond.) (1983) 90:371-384 